\title{
Bio-Efficacy of Tractor Operated Automatic Gun Sprayer
}

\author{
T. Nageshkumar ${ }^{1 *}$, M. Anantachar ${ }^{1}$, M. Veerangouda ${ }^{1}$, K.V. Prakash ${ }^{1}$, \\ Sushila Nadagouda ${ }^{2}$ and B.G. Koppalkar ${ }^{3}$ \\ ${ }^{1}$ Department of Farm Machinery and Power Engineering ${ }^{2}$ Department Entomology, \\ ${ }^{3}$ Department Agronomy, College of Agricultural Engineering, \\ UAS, Raichur-584104, Karnataka, India \\ *Corresponding author
}

\section{A B S T R A C T}

\begin{tabular}{|l|}
\hline Ke y w or d s \\
$\begin{array}{l}\text { Pod borer, Insects and } \\
\text { pests, Tractor operated } \\
\text { gun sprayer }\end{array}$ \\
\hline Article Info \\
\hline $\begin{array}{l}\text { Accepted: } \\
17 \text { July } 2018 \\
\text { Available Online: } \\
10 \text { August } 2018\end{array}$ \\
\hline
\end{tabular}

Crop yield is reduced mainly due to attack of pests, diseases and weeds. In India, crops are affected by over 200 major pests, 100 plant diseases, hundreds of weeds and other pests like nematodes, harmful birds and rodents. Approximately, 18 per cent of Indian crop yield potential is being lost due to insects, diseases and weeds which in terms of quantity would mean 30 million tonnes of food grain. The value of total loss estimated at Rs 50,000 million, representing about 18 per cent of the

\section{Introduction}

The study was conducted to evaluate the two sprayers for bioefficacy was carried out in cotton (Bt) and pigeonpea at the farmer's field, Raichur during 2017-18. The insecticide

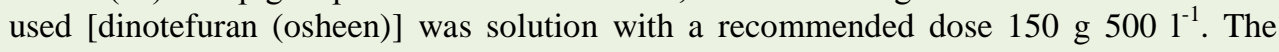
chemical used for spraying the pigeonpea crop was emamectin benzoate (ASTRA). The

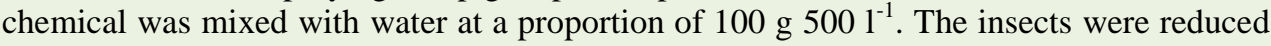
from pre counting as the number of days increased after the spraying. The populations of aphids were 10 , after 5 days reduced to 2.5 numbers. Conventional method of tractor operated gun spraying recorded higher pod borer population. The overall, present study concluded that tractor operated automatic sprayer is found to be superior when compared to conventional gun spraying for the management of pod borer. 
infested by various pests. Among the pests of cotton, cotton bollworms viz., American bollworm (Helicoverpa armigera), Pink bollworm (Pectinophora gossypiella) and spotted bollworms (Earias vitella) cause significant yield losses (Satyanarayan, 2016). Cotton is the highest pesticide consuming crop (36\%) followed by rice (20\%). About 10 per cent of insecticides on global basis and 45 per cent in India are being used for control of insects in cotton crop alone (Singh, 2004). It is found that, about 55 per cent of the total pesticide is being consumed on cotton in India against 5 per cent of total cultivable land accounting for 40 per cent of total production costs (Narang et al., 2015a). In Karnataka, cotton occupies an area of 4.66 lakh hectare with a production of 10.15 lakh bales and with a productivity of $370 \mathrm{~kg}$ lint per hectare (Anon., 2010).

Red gram (Cajanus cajan millsp.) is an important pulse crop in India. It is also known as Pigeonpea, Arhar and Tur. Red gram is mainly cultivated and consumed in developing countries of the world including India. India is the largest producer and consumer of Red gram in the world and produced 3.17 million tonne in the year 2014-15 under the area of 3.88 million hectare. Maharastra state is the largest producer of redgram accounting for 28.83 per cent of total production followed by Karnataka. In Karnataka state, area under redgram crop 6.81 lakh hectare with a production of 4.85 lakh tonnes and productivity of $712.19 \mathrm{~kg} \mathrm{ha}^{-1}$. The red gram crop is highly susceptible to insect attack. The pest and disease infection is a serious problem during the plant growth. Among the many factors responsible for low yields of pigeonpea in India, insect, pests are the major ones. Though the pest spectrum of pigeonpea crop includes 200 insects and mites, the major insect causing heavy loss is the pod borer, Helicoverpa armigera (Hubner) (Kapasi et al., 2013). Pod borers caused 60 to 90 per cent loss in the grain yield under favourable conditions and damage of seed by pod fly ranged from 14.3 to 46.6 per cent (Jail et al., 2014).

The efficacy of insecticides in the insect management is mainly influenced by the amount of chemical used in a unit area of target, deposit of the chemical on the area and percentage of the target area receiving the pesticides. The above three factors viz., dose, distribution and coverage are dependent on the droplet size and density of the chemical ((Kapasi et al., 2013). Commonly used spray equipments are conventional tractor operated gun sprayer and tractor operated automatic gun sprayer. These sprayers were evaluated for their effectiveness in reducing pest and diseases.

\section{Materials and Methods}

The tractor operated automatic gun sprayer was evaluated its effectiveness against some of the insects and pests present in the cotton and pigeonpea. Evaluation of tractor operated automatic gun sprayer was carried out in cotton $(\mathrm{Bt})$ and pigeonpea at the farmer's field, Raichur during 2017-18. The efficacy of tractor operated automatic gun sprayer was carried out at the parameters which are optimized in the field studies.

\section{Cotton}

For calculation of bio-efficacy in the field, number of pests in the field was counted from 10 randomly selected plants. The pests were counted from a total of 3 leaves of a plant i.e. upper and lower side was recorded before and after the spray leaving the border rows. The pests count was further recorded on $3^{\text {rd }}$ and $5^{\text {th }}$ day after spraying. The difference of number of pests before and after the spray was noted to calculate the percentage reduction of pests. The main sucking pests present in cotton were 
aphids and leaf hopper. The insecticide used [dinotefuran (osheen)] was solution with a recommended dose $150 \mathrm{~g} 500 \mathrm{l}^{-1}$.

\section{Pigeonpea}

The efficacy of pigeonpea crop was also measured during the field test. The chemical used for spraying the pigeonpea crop was emamectin benzoate (ASTRA). The chemical was mixed with water at a proportion of $100 \mathrm{~g}$ $5001^{-1}$. The major pest recorded was pod borer Helicoverpa armigera. The efficacy was measured by taking the number of larva present a day before spraying and number of larva present at 3 days and 5 days after spraying per plant.

At the time of harvest per cent pod damage was estimated by counting the total number of pods and the affected pods on five randomly selected plants in each treatment.

\section{Results and Discussion}

The data representing the efficacy of insecticides and pesticide against insects and pests is given in the Table 1 and 2 . The insects were reduced from pre counting as the number of days increased after the spraying. This is because of the toxic effect of insecticide on insects.

The leaf hoppers were 5.0 before spraying reduced to 1.0. In case of $\mathrm{T} 2$ (conventional tractor operated gun sprayer) pre count leaf hoppers were 6.0 reduced to 2.8 after 5 days of spraying.

The populations of aphids were 10 , after 5 days reduced to 2.5 numbers. Pre counts of aphids were 13 before spraying in conventional sprayer reduced to 4.2 numbers. This shows that automatic sprayers were effective against cotton sucking pest.

Table.1 Bio-efficacy of spraying against leaf hopper in cotton

\begin{tabular}{|c|c|c|c|}
\hline \multirow{2}{*}{ Treatment } & \multicolumn{3}{|c|}{ Population of leaf hopper (No. of hoppers leaf ${ }^{-1}$ ) } \\
\hline & Pre count & 3 DAS & 5 DAS \\
\hline T1 & 5.0 & 2.0 & 1.0 \\
\hline T2 & 7.0 & 4.0 & 2.8 \\
\hline
\end{tabular}

DAS: Days after spraying

Table.2 Bio-efficacy of spraying against aphids in cotton

\begin{tabular}{|c|c|c|c|}
\hline \multirow{2}{*}{ Treatment } & \multicolumn{3}{|c|}{ Population of aphids (No. of aphids leaf ${ }^{-1}$ ) } \\
& Pre count & 3 DAS & 5 DAS \\
\hline T1 & 10 & 6.5 & 2.5 \\
\hline T2 & 13 & 7.0 & 4.2 \\
\hline
\end{tabular}

DAS: Days after spraying

Table.3 Bio-efficacy of spraying against Helicoverpa armigera in pigeonpea crop

\begin{tabular}{|c|c|c|c|c|}
\hline \multirow{2}{*}{ Treatment } & \multicolumn{3}{|c|}{ Population of Helicoverpa armigera (No. of larva plant (N) $^{-1}$ ) } \\
\cline { 2 - 5 } & Per cent pod damage & DBS & 3 DAS & 5 DAS \\
\hline T1 & 15 & 4.2 & 2.2 & 0.8 \\
\hline T2 & 18 & 6.0 & 3.5 & 2.2 \\
\hline
\end{tabular}

DBS: Day before spraying

DAS: Days after spraying 
Bio-efficacy of spraying against Helicoverpa armigera in pigeonpea crop is presented in Table 3. It shows that population of Helicoverpa armigera was 4.2 numbers reduced to 0.8 numbers after 5 days whereas in conventional method it was 6.0 number reduced to 2.2 numbers.

The pod damage by Helicoverpa armigera for tractor operated automatic gun sprayer and conventional tractor operated gun sprayer were 15 and 18 per cent. Conventional method of tractor operated gun spraying recorded higher pod borer population. The overall, present study concluded that tractor operated automatic sprayer is found to be superior when compared to conventional gun spraying for the management of pod borer.

\section{References}

Anonymous, 2010, Research highlights. AICRP. Indian council of Agric. Res., p. 5-7
Gholap, B. and Mathur, R., 2013, Field evaluation of tractor operated boom sprayer of cotton crop. Int. J. Agric. Engg., 6(2): 372-374.

Kapasi, M., Yelshetty, S., Mekali, J. and Haveri, R., 2013, Evaluation of $\mathrm{HaNPV}$ 100 LE in different sprayers for management of pigeonpea pod borer Helicoverpa armigera (Hubner). $J$. Biopest., 6(1): 22-25.

Manncsa, 2009, Pesticides in Agriculture, Agropedia. p. 265.

Narang, M. K., Mishra, A., Kumar, V., Thakur, S. S., Singh, M. and Mishra, P. K., 2015a, Field evaluation of manual spraying technology against white flies on cotton crop in south-west Punjab. Agric. Engg. Today. 39(1): 229-33.

Satyanarayan, 2016, Design, development and evaluation of animal drawn intra canopy sprayer. Unpublished Ph. D Thesis. Univ. Agric. Sci., Raichur (India).

Singh, 2006, Performance evaluation of air carrier sprayer for soybean crop. $M$. Tech thesis. MPUAT, Udaipur

\section{How to cite this article:}

Nageshkumar, T., M. Anantachar, M. Veerangouda, K.V. Prakash, Sushila Nadagouda and Koppalkar, B.G. 2018. Bio-Efficacy of Tractor Operated Automatic Gun Sprayer. Int.J.Curr.Microbiol.App.Sci. 7(08): 3174-3177. doi: https://doi.org/10.20546/ijcmas.2018.708.339 